\title{
Effects of various bivalves on meiobenthic and nematode assemblages in shallow sandy sediments
}

\author{
Barbara Urban-Malinga • Mariusz Zalewski • \\ Natalie Barnes
}

Received: 7 October 2014/Revised: 9 January 2016/Accepted: 11 January 2016/Published online: 1 February 2016

(C) The Author(s) 2016. This article is published with open access at Springerlink.com

\begin{abstract}
A laboratory microcosm experiment was performed to study the effect of bivalves on meiobenthic and nematode community structures. Three bivalve species dominant in shallow coastal sediments of the southern Baltic Sea differing in terms of feeding mode, faecal deposition and sediment depth penetration (Macoma balthica, Cerastoderma glaucum and Mya arenaria) were selected as model organisms: our experiment demonstrated that although the bivalves had no overall effect on total meiobenthic densities, they variously affected a number of meiobenthic major taxa. Species buried under the sediment surface (M. balthica, M. arenaria) facilitated meiobenthos to penetrate deeper sediment layers compared to the surface-dwelling bivalves (C. glaucum). The most conspicuous response of meiobenthos and nematodes to bivalve activities was, however, observed at the sediment surface: densities of juvenile bivalves and rotifers, and the dominant nematode species
\end{abstract}

Handling Editor: Stuart Jenkins

B. Urban-Malinga $(\bowtie) \cdot$ M. Zalewski

Department of Fisheries Oceanography and Marine

Ecology, National Marine Fisheries Research Institute,

81-332 Gdynia, Poland

e-mail: basiam@mir.gdynia.pl

N. Barnes

Invertebrates Division, Life Sciences Department, The

Natural History Museum, Cromwell Road,

London SW7 5BD, UK
(Adoncholaimus thalassophygas, Desmolaimus cf. zeelandicus and Halomonhystera disjuncta) were significantly reduced in surface sediments in Macoma microcosms compared to other treatments. It is suggested that different bivalve feeding modes (deposit-feeding vs. suspension-feeding), attributes of faecal deposition (to the sediment surface vs. to subsurface sediments) and depth of sediment penetration can significantly change meiobenthic and nematode communities in sandy sediments.

Keywords Meiofauna - Nematodes - Bivalves · Baltic Sea $\cdot$ Laboratory experiment

\section{Introduction}

Bivalves are widely distributed across benthic environments and often represent the dominant component of macroinvertebrate communities, both in terms of density and biomass. They filter organic particles from the water column and transfer undigested organic and inorganic particles to the sediment in the form of faeces and pseudofaeces. Next to their filtering and biodepositional functions, bivalves act as bioturbators. Although systems of burrows built by infaunal bivalves are less complex than those built by other macrobenthic bioturbators, their feeding activitiesmoving about in the sediment and withdrawing and extending their siphons-can modify the physical 
structure and chemistry of sediments (Dame, 1993; Jones et al., 1994; Gili \& Coma, 1998; Gutierrez et al., 2003). Through these modifications, bivalves affect transport rates in the sediment, facilitate oxygen exchange and penetration into sediments (Levinton, 1995; Dame, 1996) and stimulate microbial metabolism, thus affecting other benthic organisms (Olafsson, 2003 and references therein).

Even though it is known that bivalves alter sediment processes, being among the most conspicuous and well-studied invertebrates in the marine environment, their effect on meiofaunal assemblages is relatively poorly studied. Research to date has focused on the effects of single bivalve species locally important in specific geographical regions, sediment types and/or environments (Olafsson \& Elmgren, 1991; Olafsson et al., 1993; Warwick et al., 1997; Austen et al., 1998; Olafsson, 2003; Braeckman et al., 2011a). Therefore, these studies cannot be easily extrapolated to other benthic environments and regions. In addition, the available data are often contrasting (for overview see Olafsson, 2003). For instance, Reise (1983) demonstrated that the clam Macoma balthica (Linnaeus, 1758) stimulated turbellarian and nematode abundances, whilst no effect or even a reduced abundance was observed by other authors undertaking the same comparison (Olafsson et al., 1993, 2005, respectively).

Bivalve species vary considerably in terms of mobility, feeding type and activity, method of biodeposits release, and intensity of sediment disturbance. In this study we investigated the effects of three bivalve species, differing in terms of feeding mode (suspension- vs. deposit-feeding), mobility and mode of faeces deposition, on meiobenthos with emphasis on nematodes.

Cerastoderma glaucum (Bruguière, 1789), M. balthica and Mya arenaria Linnaeus, 1758 are the most common burrowing bivalves of the southern Baltic Sea, often dominating macrobenthic communities (Warzocha, 1994, 1995; Piesik et al., 2009). M. balthica is a facultative deposit feeder taking algae, bacteria and detritus from the sediment surface but is able to switch to a suspension-feeding mode depending on food availability (Ólafsson, 1986). It is found buried in the sediment usually at $2-6 \mathrm{~cm}$ depth, with its inhalant siphon extended to the sediment surface and the shorter exhalent siphon terminating below the surface. Both $M$. arenaria and $C$. glaucum are suspension feeders taking their food out of the water column but their lifestyles in the sediment differ considerably. The soft-shell clam Mya buries deeply $(10-25 \mathrm{~cm})$ and leads a sessile lifestyle extending its single, long siphon (inhalant and exhalant siphons are fused) to the sediment surface. It can have a profound effect on sediment biochemistry due to leakage of water from the shell (Hansen et al., 1996). The cockle Cerastoderma has two short, separate siphons and lives actively in the upper few centimetres $(0-3 \mathrm{~cm})$, mixing sediment particles and therefore acting as a biodiffuser. Both suspension feeders eject their faeces and pseudofaeces to the sediment surface, whilst Macoma releases them in the subsurface sediment (Ólafsson, 1986; Olafsson et al., 1993). Bivalve biodeposits are rich in carbon and nitrogen (Kautsky \& Evans, 1987) and may organically enrich sediments and promote the development of the microbial community. It is hypothesized here that the vertical distribution of meiobenthos and nematodes, and nematode community composition and structure are affected by the presence and species identity of bivalves.

\section{Materials and methods}

Characteristics of the study site

Sediment and bivalves for the experiment were collected from a sheltered site located in the inner part of Puck Bay (near Chałupy, Polish Baltic coast), at 70-80 cm water depth. Sediment at the study site was a well-sorted sand dominated by the medium fraction $(0.25-0.5 \mathrm{~mm}$; on average $80 \%)$, followed by fine $(0.1-0.25 \mathrm{~mm} ; 9 \%)$ and coarse sand $(0.5-$ $1.0 \mathrm{~mm} ; 9 \%$ ). Organic carbon and total nitrogen (TN) contents averaged 0.06 and $0.02 \%$, respectively, whilst sediment chlorophyll $a$ and phaeophytin concentrations were 1.8 and $0.7 \mu \mathrm{g} g$ dry sediment ${ }^{-1}$, respectively (Urban-Malinga et al., 2014).

\section{Sediment and fauna sampling}

The experiment was performed in September 2009. Triplicate sediment cores with a surface area of $10 \mathrm{~cm}^{2}$ were collected randomly at the study site to determine the abundance and structure of the meiobenthic community, hereafter referred to as the field community. Sediment cores were sliced 
immediately on sampling into seven depth layers: $0-1$, $1-2,2-3,3-4,4-5,5-10$ and $10-15 \mathrm{~cm}$. These slices were preserved separately in neutral $4 \%$ formaldehyde and were further processed in accordance with methods described below for meiofauna in the experiment. Nematode densities and assemblage structure of the field community served as a field control.

Sediment samples for the experiment were taken with a core tube with a $225 \mathrm{~cm}^{2}$ surface area to a depth of $10 \mathrm{~cm}$. The sediment was immediately sieved over $1-\mathrm{mm}$ mesh in a small amount of ambient seawater to exclude macrofauna but to retain all interstitial biota. This may have also excluded larger meiofauna, and although we acknowledge this is not ideal, it was felt to be the most replicable method of eliminating the macrofaunal component. In the laboratory, the sediment was gently homogenized by hand and put into plexiglass cores, $12.3 \mathrm{~cm}$ internal diameter and $33 \mathrm{~cm}$ long, to a depth of $15 \mathrm{~cm}$. These sediment cores were then placed in a water bath with a total volume of $1100 \mathrm{dm}^{3}$, connected to a reservoir of $2400 \mathrm{dm}^{3}$ equipped with a cooling system and an open-loop seawater pumping system. Water for the system was transported directly from the sea over a distance of $50 \mathrm{~m}$, it was filtered through a 2-mm mesh to remove large organic particles and fauna but to retain natural concentrations of phytoplankton and other organic suspensions. Water from the system was distributed to the cores via plastic tubes to facilitate turnover of overlying water $(15 \mathrm{~cm}$ deep). Outflow water was recycled. Water in the whole system was replaced with fresh seawater once per week. The sediment was allowed to stabilize for 14 days before experiments commenced: preliminary experiments showed that the vertical pattern of meiofauna distribution as recorded at the study site (with the highest meiofauna concentrations at the sediment surface, $0-3 \mathrm{~cm}$ ) was reestablished after this period (Urban-Malinga et al., 2014). The three bivalve species dominating shallow benthic environments of the Gulf of Gdańsk were selected for the study: M. balthica, M. arenaria and $C$. glaucum (Warzocha, 1994, 1995; Piesik et al., 2009).

Intact specimens were chosen for the experiment: Cerastoderma (9-14 mm, 0.2-0.7 g w. wt.), Macoma (12-15 mm, 0.2-0.4 g w. wt.) and Mya (15-25 mm, $0.3-1.2 \mathrm{~g} \mathrm{w}$. wt.). Specimens were added to the microcosms to obtain mono-specific treatments (hereafter referred to as Macoma, Mya and Cerastoderma) of a total bivalve biomass $(2.1 \mathrm{~g} \mathrm{w}$. wt. per core) similar to that recorded in the field during the study period (a mean of $170 \mathrm{~g} \mathrm{w}$. wt. $\mathrm{m}^{-2}$; the three bivalve species selected for this study are the only bivalves at our study site). Biomass (live wet weight) was estimated by weighing each specimen to the nearest $0.1 \mathrm{~g}$. Wet weight excluded water inside the valve (30\% of total bivalve weight, pers. obs.) but included shell weight. Densities of Cerastoderma and Mya introduced to the microcosms (on average 7 and 3 ind. per core corresponding to 610 and 280 ind. $\mathrm{m}^{-2}$, respectively) were within the range of their natural densities recorded in the field (i.e. Cerastoderma: 178-889 ind. $\mathrm{m}^{-2}$, Mya: $15-340$ ind. $\mathrm{m}^{-2}$ ), whilst the densities of Macoma (on average 6 ind. per core corresponding to 470 ind. $\mathrm{m}^{-2}$ ) exceeded these ranges (30-320 ind. $\mathrm{m}^{-2}$ ). We have used standardized biomass since the densities appropriate for the experiment (e.g. corresponding to average field densities of Cerastoderma or Macoma) would result in unnaturally high densities and biomass of Mya.

Each treatment with bivalves and the control treatment with no macrofauna were performed with three replicate cores.

The majority of specimens buried into the sediment within half an hour of adding to the mesocosms. It was assumed that specimens which had not buried within this time were dead or damaged, and these were replaced. The microcosms were then incubated at $14^{\circ} \mathrm{C}$ (the ambient temperature at the time of sampling) for 1 month. During this time each microcosm was monitored to control water temperature and overlying water exchange rates and to remove and replace any dead specimens (with an animal of similar size) appearing on the sediment surface. After 1 month, samples for meiofauna and sediment characteristics were taken.

Total organic carbon and total nitrogen contents

Sediment cores for determination of total organic carbon (TOC) and TN contents were collected from each microcosm with a cut-off syringe with an inner diameter of $1.4 \mathrm{~cm}$. Each core was sliced into the following depth layers: $0-1,1-2,2-3,3-4,4-5$ and $5-10 \mathrm{~cm}$. The sediment samples were then frozen at $-20^{\circ} \mathrm{C}$ before further analysis. TOC and TN contents were measured with a Perkin Elmer CHNS/O analyzer after removal of carbonates and drying at $60^{\circ} \mathrm{C}$ for $24 \mathrm{~h}$. 
Pore water nutrient content

For pore water nutrient analysis, one core with an inner diameter of $3.6 \mathrm{~cm}$ was sampled from each microcosm and was sliced into the following depth layers: 0-1, 1-2, 2-3, 3-4, 4-5 and 5-10 cm. Samples were frozen at $-20^{\circ} \mathrm{C}$ and then thawed at room temperature prior to analysis. Due to the small amount of pore water obtained from each sediment slice, replicate slices were pooled together. The pore water was extracted with ultra pure water and filtered on a $0.7-\mu \mathrm{m}$ glass filter. Ammonium and phosphate concentrations were measured immediately after extraction according to standard methods recommended for the Baltic Monitoring Program (Grasshoff et al., 1983).

\section{Meiofauna}

One sediment core with an inner diameter of $3.6 \mathrm{~cm}$ and a cross-sectional area of $10 \mathrm{~cm}^{2}$ was sampled from each microcosm for determination of the meiofaunal community composition and structure. Sediment cores were sliced immediately into seven depth layers: 0-1, $1-2,2-3,3-4,4-5,5-10$ and $10-15 \mathrm{~cm}$, and each slice was preserved with a neutral $4 \%$ formaldehyde solution. Prior to the analysis, samples were first rinsed over a 1-mm mesh to remove macrofauna. Meiofauna was extracted by re-suspending the sediment and decanting the overlying water 10 times over a $38-\mu \mathrm{m}$ mesh sieve. The fraction retained on the sieve was preserved with a $4 \%$ formaldehyde solution and stained with rose bengal. Meiofauna were counted and identified to higher taxon level under a stereomicroscope, and the first 120 nematodes encountered in each sediment slice were picked out and mounted on permanent glycerin slides. Nematodes were identified to the lowest possible taxonomic level (genus/species) using the NEMYS database (Steyaert et al., 2005) and literature therein and the Linnaean Society keys to Nematoda (Platt \& Warwick, 1983, 1988; Warwick et al., 1998). Wieser's (1953) classification was used to distinguish four trophic groups: selective $(1 \mathrm{~A})$ and non-selective (1B) deposit feeders, epistrate feeders (2A), and predators/omnivores (2B).

Diversity measures were calculated based on the nematode abundance data in the integrated sediment column $(0-15 \mathrm{~cm})$. As a fixed number of individuals was identified, several different diversity measures were calculated in order to compare species richness and diversity between treatments. Diversity was expressed by the Margalef's species richness (d), Pielou's evenness $\left(J^{\prime}\right)$, Shannon-Wiener diversity index $\left(H^{\prime}\right)$ and the rarefaction index $\operatorname{ES}(x)$ (expected number of species). One knot of 30 was used [ES(30)] (i.e. the lowest number of nematodes recorded in one sample) to allow comparisons between different treatments. In order to compare diversity among treatments, the number of nematodes used for calculating the diversity indices was standardized to $30 \%$ of the total number of nematodes in the microcosm (i.e. the minimum percentage of nematodes sorted for any core). This was done by randomly selecting $30 \%$ of individuals from all nematodes recorded in all depth layers in a given microcosm.

Statistical analysis

The effects of treatment on the total densities of meiofauna and selected major taxa in the integrated sediment column were studied by one-way PERMANOVA with the factor Treatment (TR) with four fixed levels (Control, Macoma, Mya, Cerastoderma). The same procedure but with five fixed levels (Control, Field, Macoma, Mya, Cerastoderma) was used to test for differences in nematode densities between the experimental treatments and field community. Univariate data analyses were performed on Euclidean distance based resemblance matrices using unrestricted permutations of raw data. Multivariate analyses were performed using a three-way crossed PERMANOVA. The experimental design consisted of three factors: Treatment (TR; fixed, with four levels), sediment Depth (DE; fixed, with seven levels) and Replicate (RE; random, with three levels) nested within Treatment (TR). The application of PERMANOVA (permutational ANOVAs that can be used as univariate ANOVAs with $P$-values obtained with permutation) and nesting the replicates within treatment is a way to deal with the lack of independency of data since the different slices originate from the same core (Braeckman et al., 2011a, b; Urban-Malinga et al., 2014). The analyses of effects of treatment on the vertical profiles of total meiofauna and nematode densities, nematode community structure (composition and densities of nematode species), and organic carbon, TN, and pore water nutrient contents were performed on both raw (to take differences in 
species/genus abundance into account) and standardized (to account for differences in total nematode abundances among treatments) untransformed, square- and fourth-root transformed nematode genera abundance data (to discriminate between the effects of bivalves on more common and rare genera). Euclidean distance and Bray-Curtis-based resemblance matrices were used for abiotic and biological data, respectively. The Bray-Curtis similarity measure is undefined for two empty samples (sediment depth slices with no meiofauna), and therefore, the zero-adjusted BrayCurtis resemblance matrix was used, in which a dummy species is added to all samples in the original abundance matrix. Abiotic data (organic carbon, TN and pore water nutrient contents) were normalized prior to analysis. PERMANOVA analyses were conducted using 9999 permutations of residuals under a reduced model. Significant interaction effects were further investigated using a posteriori pairwise comparisons of factor TR within levels of TR $\times$ DE. Pairwise tests were based on $P$ values calculated using the 9999 Monte-Carlo permutations procedure [i.e. $P(\mathrm{MC})]$. Homogeneity of multivariate dispersion across groups was tested prior to a posteriori pairwise comparisons by means of PERMDISP. Distances of group members to the group centroids were tested by permutation within RE (TR) groups (averaged Depths) and in TR $\times$ DE groups (averaged Replicates).

Non-metric multi-dimensional scaling (MDS) ordinations were used to visualize the similarities between the treatments and replicates. Analysis of similarity percentages (SIMPERs) was performed to determine the contribution of individual species to the average Bray-Curtis dissimilarity between treatments. SIMPER and PERMANOVA analyses were carried out using the software package PERMANOVA+ for PRIMER (Anderson et al., 2008).

\section{Results}

Survival of macrofauna

All but three macrofauna specimens initially added to the microcosms were alive at the end of the experiment. The exceptions were two Cerastoderma individuals and one Macoma specimen, which were found dead at the sediment surface after 2 weeks of incubation and replaced.
In control cores, an oxidized surface zone of 10-15 mm was evident, below which the sediment was grey or greyish-black. In the Cerastoderma treatments, the depth range of the oxidized zone was not visibly different, whilst in the Macoma treatments, it was always extended to a depth of 4-5 cm. Microcosms with Mya either had no clearly visible changes to the oxidized zone or it extended much deeper, up to $10 \mathrm{~cm}$ depth. Slicing sediment cores from the microcosms at the end of the experiment demonstrated that Macoma was concentrated mainly in the upper $6 \mathrm{~cm}$, whilst $M y a$ was noted in the upper $10 \mathrm{~cm}$ and Cerastoderma in the upper $2 \mathrm{~cm}$.

\section{Sediment characteristics}

Average TOC values were enhanced in the upper $4 \mathrm{~cm}$ in the Mya treatment, whilst TN contents were lower in the top sediment layer in the Macoma treatment compared to the control and other treatments (Fig. 1). Pore water ammonium concentrations in surface sediments were lower in Macoma and Cerastoderma microcosms compared to the control, whilst in the Mya treatment ammonium content peaked in the topmost sediment and was reduced in deeper sediment layers (Fig. 2). PERMANOVA showed, however, no effect of treatment on vertical profiles of pore water nutrients concentrations, organic carbon or TN contents (Table 1).

\section{Effects on meiofauna}

\section{Total abundances}

Average total abundances of meiofauna (integrated over the sediment column) recorded in the Mya and Cerastoderma microcosms at the end of the experiment were higher than those in the sediment devoid of macrofauna [means $( \pm \mathrm{SD}): 658( \pm 360)$ and 587 $( \pm 156)$ vs. $412( \pm 47)$ ind. $10 \mathrm{~cm}^{-2}$, respectively], and lowest in the Macoma treatment $[179( \pm 112)$ ind. $10 \mathrm{~cm}^{-2}$ ] (Fig. 3). These differences were not, however, statistically significant (PERMANOVA, Table 3). Nematodes numerically dominated all treatments, ranging from $58 \%$ of the total meiofaunal abundance with Cerastoderma to $88 \%$ with Macoma. In addition, juvenile bivalves and rotifers were 


\section{Organic carbon [\%]}
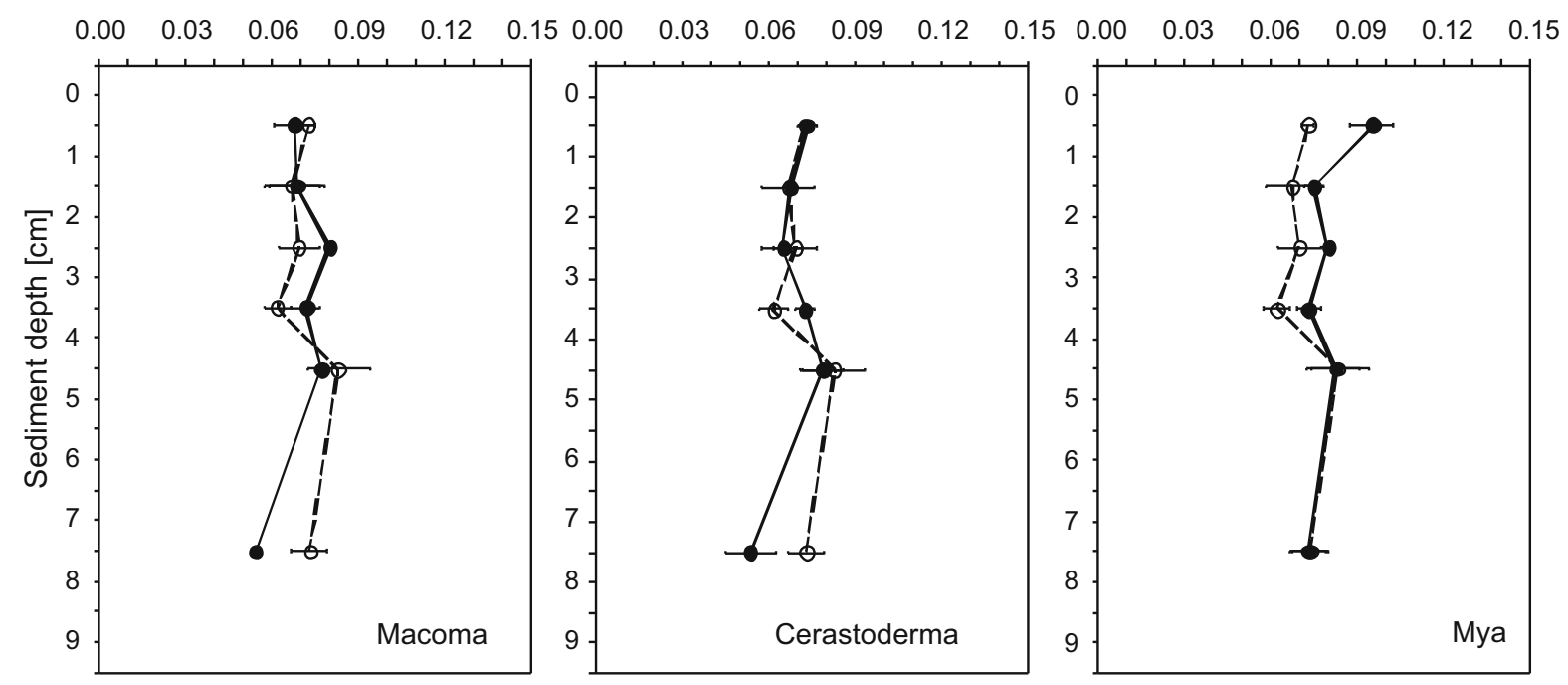

Total nitrogen [\%]
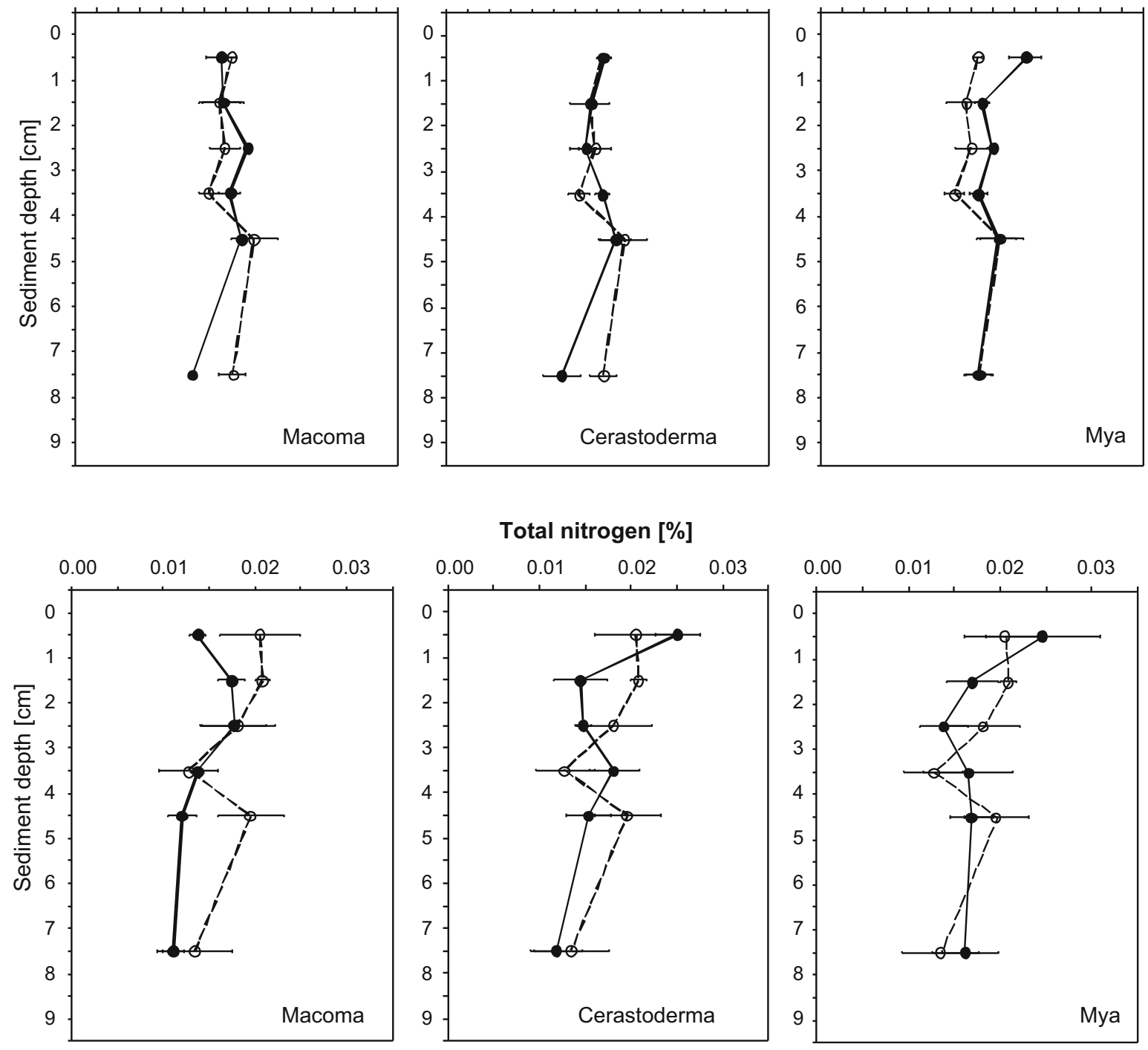

Fig. 1 Vertical profiles of organic carbon and total nitrogen content in each microcosm treatment at the end of the experiment (mean $\pm \mathrm{SE}$; control: empty dots, treatments with bivalves: filled dots)

numerically important groups, constituting $11-20 \%$ of the total meiobenthic density in treatments with Cerastoderma and Mya, and 0-7\% in the Macoma treatment and defaunated sediment, respectively (Fig. 3). There were significant differences in their abundance across treatments (Table 3). In contrast, integrated nematode abundances at the end of the experiment [means $( \pm \mathrm{SD})$ : $158( \pm 88)-462( \pm 70)$ ind. $10 \mathrm{~cm}^{-2}$ ] were not statistically different across treatments (PERMANOVA, Table 3).
Nematodes in the experiment versus in the field

Total nematode densities recorded in the microcosms at the end of the experiment were not significantly different from those recorded in the field on the day of sediment sampling [PERMANOVA: $\mathrm{MS}=44,252$, Pseudo- $F=1.53, P($ perm $)=0.26]$. However, the nematode assemblages differed significantly [PERMANOVA: $\mathrm{MS}=1257$, Pseudo- $F=2.4, P($ perm $)=$ 0.003 , respectively]. Pairwise tests showed that the 


\section{Ammonium N-NH ${ }_{4}\left[\mu \mathrm{mol} \mathrm{dm}{ }^{-3}\right]$}
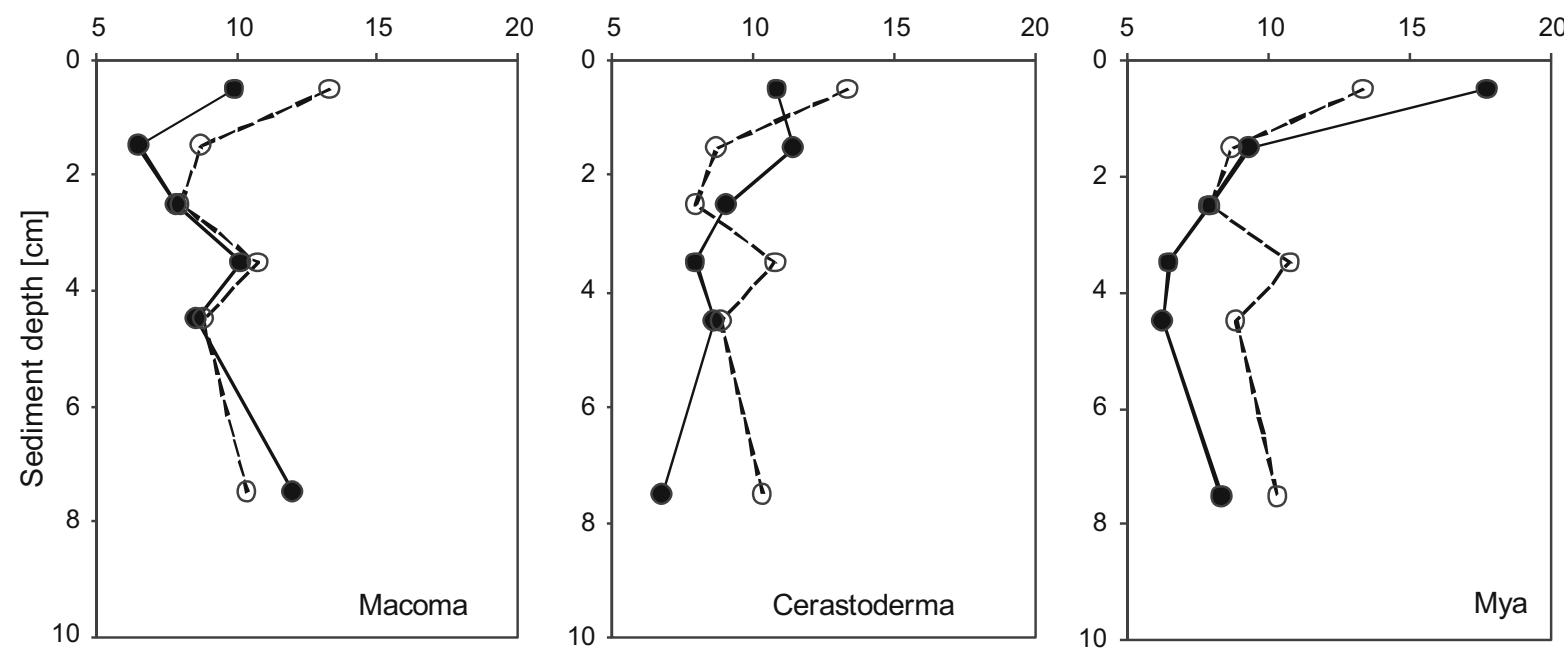

Phosphate $\mathrm{P}_{-} \mathrm{PO}_{4}\left[\mu \mathrm{mol} \mathrm{dm}{ }^{-3}\right]$
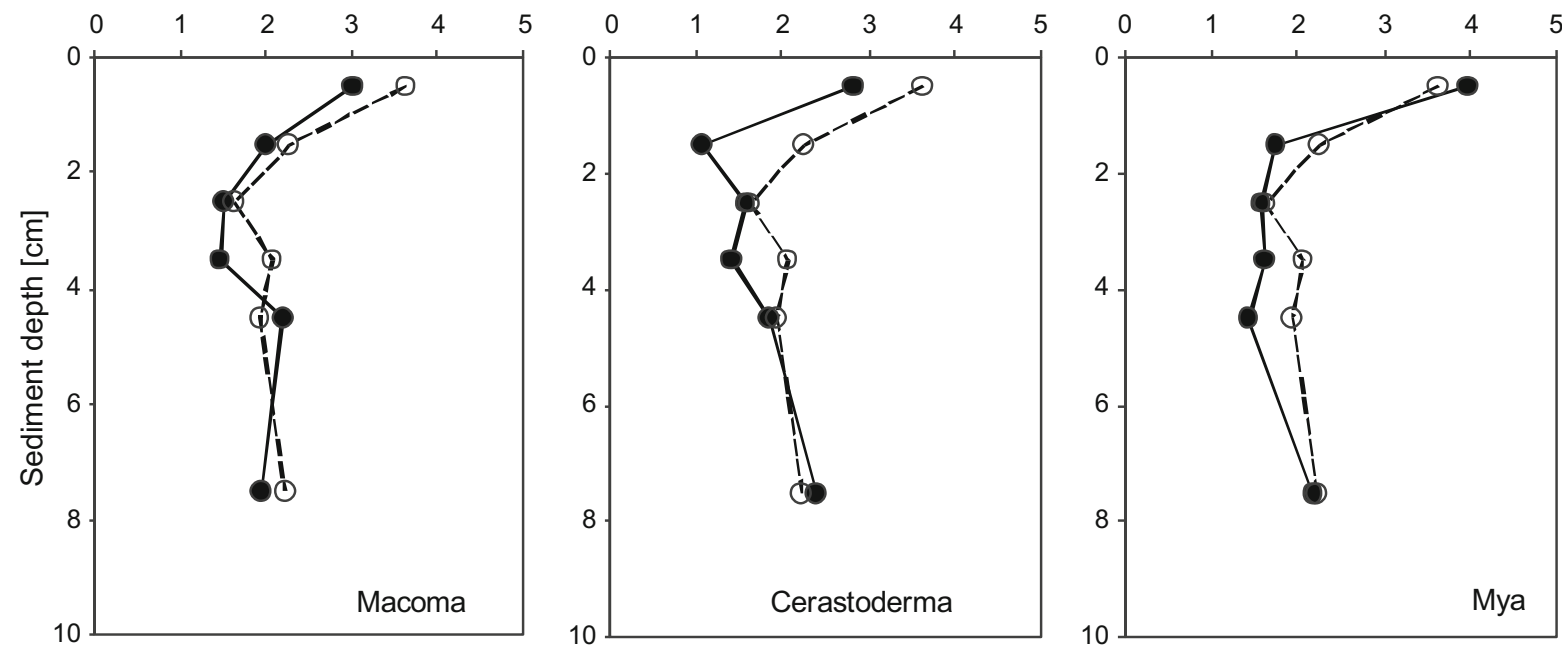

Fig. 2 Vertical profiles of pore water ammonium and phosphates concentrations in each microcosm treatment at the end of the experiment (three replicates integrated; control: empty dots, treatments with bivalves: filled dots)

field community varied significantly from those recorded in experimental treatments $[P(\mathrm{MC})<0.05]$ except for the Macoma treatment $[P(\mathrm{MC})>0.05]$. SIMPER analysis of the presence/absence data revealed that differences in the nematode composition were mainly due to the following genera: Daptonema, Tripyloides, Viscosia, Eleutherolaimus and Calomicrolaimus (data not shown). Viscosia and Eleutherolaimus were present in the field but not recorded in the microcosms, whilst the densities of Tripyloides, Daptonema and Calomicrolaimus were strongly reduced under experimental conditions (Table 2). Integrated nematode abundances at the end of the experiment [means ( $\pm \mathrm{SD}): 158( \pm 88)-462( \pm 70)$ ind. $10 \mathrm{~cm}^{-2}$ ] were not statistically different compared to the field community [447 $( \pm 65)$ ind. $10 \mathrm{~cm}^{-2}$; PERMANOVA: $\mathrm{MS}=44,252$, Pseudo- $F=1.53, P($ perm $)=0.261]$.

Nematode community structure

In total, 26 nematode genera including 5 multispecies genera and 21 species were recorded (Table 2). 
Table 1 Results of PERMANOVA analyses for differences in vertical profiles of pore water nutrients and organic carbon and total nitrogen contents, total meiobenthic and nematode abundances, multivariate nematode community structure and selected nematode abundances among treatments and sediment depths at the end of the experiment

\begin{tabular}{|c|c|c|c|c|c|c|c|c|c|c|c|c|}
\hline & \multicolumn{4}{|c|}{ Treatment } & \multicolumn{4}{|c|}{ Depth } & \multicolumn{4}{|c|}{ Treatment $\times$ Depth } \\
\hline & df & MS & Pseudo- $F$ & $P$ & df & MS & Pseudo- $F$ & $P$ & df & MS & Pseudo- $F$ & $P$ \\
\hline$C_{\text {org }}$ & 3 & 2.767 & 3.32 & ns & 5 & 2.826 & 3.92 & 0.007 & 15 & 0.87 & 1.21 & ns \\
\hline$N_{\text {tot }}$ & 3 & 1.218 & 1.39 & ns & 5 & 2.509 & 2.86 & 0.028 & 15 & 0.85 & 0.97 & ns \\
\hline $\mathrm{N}-\mathrm{NH}_{4}$ & 3 & 0.151 & 0.18 & ns & 5 & 2.054 & 2.51 & ns & & & & \\
\hline $\mathrm{P}-\mathrm{PO}_{4}$ & 3 & 0.391 & 1.7 & ns & 5 & 3.673 & 15.95 & 0.0002 & & & & \\
\hline Total meiofauna densities & 3 & 19,409 & 3.24 & ns & 6 & 2.67 & 85.04 & 0.0001 & 18 & 21,507 & 6.86 & 0.0002 \\
\hline Nematode densities & 3 & 6929 & 1.67 & ns & 6 & 1.29 & 70.90 & 0.0001 & 18 & 8400 & 4.62 & 0.0002 \\
\hline Nematoda: untransformed & 3 & 1696 & 0.50 & ns & 6 & 14,230 & 12.27 & 0.0001 & 18 & 1296 & 1.12 & ns \\
\hline Square-root transformed & 3 & 1231 & 0.39 & ns & 6 & 12,850 & 14.31 & 0.0001 & 18 & 968 & 1.08 & ns \\
\hline Fourth-root transformed & 3 & 1068 & 0.36 & ns & 6 & 11,842 & 14.95 & 0.0001 & 18 & 845 & 1.07 & ns \\
\hline A. thallasophygas & 3 & 120 & 2.13 & ns & 6 & 1399 & 72.96 & 0.0001 & 18 & 9266 & 4.83 & 0.0002 \\
\hline D. cf. zeelandicus & 3 & 16.94 & 0.45 & ns & 6 & 105.97 & 7.26 & 0.0002 & 18 & 29.27 & 2.01 & 0.0329 \\
\hline A. elongatus & 3 & 9.32 & 0.76 & ns & 6 & 18.06 & 3.27 & 0.0097 & 18 & 6.19 & 1.12 & ns \\
\hline H. disjuncta & 3 & 10.62 & 4.02 & ns & 6 & 70.46 & 41.15 & 0.0001 & 18 & 9.06 & 5.29 & 0.0001 \\
\hline
\end{tabular}

Fig. 3 Total meiofauna numbers (mean $\pm \mathrm{SE}$ ) and numerical abundance of the dominant major taxa in each microcosm treatment at the end of the experiment

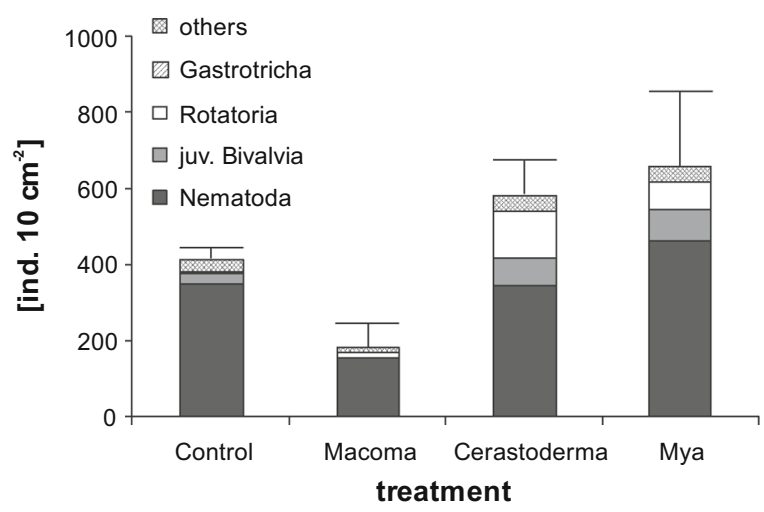

Macoma microcosms was separated from those in other treatments. There was no effect of treatment on nematode community structure when raw data were analysed.

Diversity indices $\left[d, J^{\prime}, H^{\prime}, \operatorname{ES}(30)\right]$ were not statistically different across treatments $[P($ perm $)<$ 0.05] (Table 3).

Vertical distribution

The majority of meiobenthos in the control and in the microcosms with Mya and Cerastoderma were recorded at the sediment surface (87-96\%), whilst in the Macoma treatment, $46 \%$ of meiobenthos penetrated deeper sediment layers (Fig. 5). Vertical 
Table 2 Average (mean \pm SE) abundances (ind. $10 \mathrm{~cm}^{-2}$ ) of nematode species in the natural environment and in each treatment at the end of the experiment

\begin{tabular}{|c|c|c|c|c|c|c|}
\hline \multirow[t]{2}{*}{ Species } & \multirow{2}{*}{$\begin{array}{l}\text { Trophic } \\
\text { groups }\end{array}$} & \multicolumn{5}{|l|}{ Treatment } \\
\hline & & Field & Control & Macoma & Cerastoderma & Mya \\
\hline Adoncholaimus thalassophygas & $2 \mathrm{~B}$ & $90.3 \pm 24.7$ & $148.6 \pm 16.3$ & $37.0 \pm 14.3$ & $98.1 \pm 4.5$ & $192.2 \pm 101.6$ \\
\hline Anoplostoma viviparum & $1 \mathrm{~B}$ & $41.8 \pm 17.6$ & $16.6 \pm 6.0$ & $5.3 \pm 2.3$ & $18.5 \pm 9.4$ & $16.9 \pm 3.9$ \\
\hline Ascolaimus elongatus & $1 \mathrm{~B}$ & $4.3 \pm 1.9$ & $7.6 \pm 5.4$ & $17.0 \pm 8.5$ & $6.7 \pm 1.7$ & $10.1 \pm 4.5$ \\
\hline Axonolaimus spinosus & $1 \mathrm{~B}$ & $17.3 \pm 1.8$ & $14.0 \pm 8.2$ & $8.0 \pm 1.0$ & $24.9 \pm 7.1$ & $30.6 \pm 11.4$ \\
\hline Calomicrolaimus cf. honestus & $2 \mathrm{~A}$ & $19.7 \pm 8.4$ & $0.8 \pm 0.8$ & $4.0 \pm 3.0$ & & \\
\hline Chromadorita spp. & $2 \mathrm{~A}$ & $8.5 \pm 3.4$ & $6.1 \pm 1.7$ & $3.7 \pm 0.9$ & $10.5 \pm 6.6$ & $8.0 \pm 3.4$ \\
\hline Daptonema aff. setosus sp. A & $1 \mathrm{~B}$ & $10.5 \pm 3.3$ & & $0.3 \pm 0.3$ & $3.8 \pm 2.0$ & $2.2 \pm 2.2$ \\
\hline Desmolaimus cf. zeelandicus & $1 \mathrm{~B}$ & $56.3 \pm 23.4$ & $53.9 \pm 11.1$ & $15.7 \pm 12.3$ & $51.9 \pm 21.7$ & $37.2 \pm 22.5$ \\
\hline Dichromadora cephalata & $2 \mathrm{~A}$ & $2.2 \pm 0.9$ & $1.0 \pm 1.0$ & $0.3 \pm 0.3$ & & \\
\hline Diplolaimella sp. 1 & $1 \mathrm{~B}$ & $0.3 \pm 0.3$ & $0.3 \pm 0.3$ & & & \\
\hline Dorylaimus sp. 1 & 2B & & $0.3 \pm 0.3$ & & & \\
\hline Eleutherolaimus & $1 \mathrm{~B}$ & $1.7 \pm 0.9$ & & & & \\
\hline Enoplolaimus spp. & $2 \mathrm{~B}$ & $2.3 \pm 0.9$ & $1.8 \pm 0.9$ & $5.7 \pm 4.2$ & $3.8 \pm 3.8$ & $15.2 \pm 8.7$ \\
\hline Enoplus aff. brevis & $2 \mathrm{~B}$ & $2.0 \pm 1.0$ & $3.0 \pm 3.0$ & $0.7 \pm 0.3$ & $2.3 \pm 2.3$ & $0.3 \pm 0.3$ \\
\hline Halomonhystera disjuncta & $1 \mathrm{~B}$ & $0.5 \pm 0.3$ & $9.7 \pm 2.0$ & $8.7 \pm 4.3$ & $31.5 \pm 5.9$ & $56.2 \pm 21.6$ \\
\hline Hypodontolaimus spp. & $2 \mathrm{~A}$ & $42.3 \pm 8.5$ & $8.5 \pm 1.4$ & $5.7 \pm 2.0$ & $6.5 \pm 0.2$ & $4.8 \pm 2.4$ \\
\hline Leptolaimus papilliger & $1 \mathrm{~A}$ & $1.3 \pm 0.9$ & & & $0.9 \pm 0.9$ & $1.0 \pm 1.0$ \\
\hline Monhystera sp. 1 & $1 \mathrm{~B}$ & & $0.8 \pm 0.8$ & $2.0 \pm 1.2$ & & \\
\hline Oncholaimus oxyuris & $2 \mathrm{~B}$ & $38.5 \pm 6.6$ & $17.4 \pm 6.6$ & $12.0 \pm 7.0$ & $21.6 \pm 6.2$ & $25.7 \pm 8.6$ \\
\hline Paracanthonchus spp. & $2 \mathrm{~A}$ & $8.2 \pm 0.6$ & $3.0 \pm 3.0$ & $5.0 \pm 5.0$ & $11.1 \pm 5.1$ & $7.1 \pm 4.7$ \\
\hline Paracyatholaimus proximus & $2 \mathrm{~A}$ & $34.8 \pm 20.4$ & $26.4 \pm 13.2$ & $5.7 \pm 1.9$ & $26.0 \pm 8.9$ & $21.2 \pm 11.1$ \\
\hline Prochromadorella sp. 1 & $2 \mathrm{~A}$ & $0.5 \pm 0.3$ & & & $1.1 \pm 1.1$ & \\
\hline Sphaerolaimus cf. balticus & $2 \mathrm{~B}$ & $17.8 \pm 5.5$ & $20.8 \pm 8.0$ & $8.7 \pm 5.2$ & $18.3 \pm 3.1$ & $10.1 \pm 4.9$ \\
\hline Theristus flevensis & $1 \mathrm{~B}$ & $10.5 \pm 3.0$ & $6.7 \pm 3.7$ & & $4.7 \pm 1.3$ & $14.6 \pm 7.3$ \\
\hline Tripyloides marinus & $1 \mathrm{~B}$ & $27.2 \pm 4.0$ & & & & $7.6 \pm 3.8$ \\
\hline Viscosia viscosa & 2B & $8.0 \pm 3.2$ & & & & \\
\hline
\end{tabular}

profiles of both total meiobenthic and nematode abundances were significantly affected by the treatment $[P($ perm $)<0.05$, Table 1]. A posteriori tests showed that meiobenthic and nematode abundances were significantly lower in the top sediment layer $(0-1 \mathrm{~cm})$ in the Macoma treatment compared to all other treatments $[P(\mathrm{MC})<0.05$; data not shown].

No effect of treatment on the vertical profiles of nematode community structure was identified both when standardized and raw nematode abundance data were analysed (PERMANOVA, $P>0.05$; data not shown).

The vertical distribution of these dominant nematodes (Fig. 6) (A. thalassophygas, D. cf. zeelandicus, $H$. disjuncta) varied significantly across treatments $[P($ perm $)<0.05$; Table 1]. Pairwise tests showed that their abundances in the top sediment layer $(0-1 \mathrm{~cm})$ in the Macoma treatment $\left(29.0,3.7,8.7\right.$ ind $10 \mathrm{~cm}^{-2}$, respectively) were significantly lower than in other treatments $\left(95-180,15-50,9-55\right.$ ind $10 \mathrm{~cm}^{-2}$, respectively). Also other nematode species were one order of magnitude less abundant in the upper sediment in Macoma treatment than in other microcosms. Deeper sediment layers in Mya and Macoma microcosms were penetrated largely by Ascolaimus elongatus (Bütschli, 1874), D. cf. zeelandicus and A. thalassophygas.

\section{Discussion}

Our experiment demonstrated that the presence and identity of bivalves did affect vertical distribution of 
Table 3 Results of PERMANOVA analyses for differences in total abundances of meiofauna and selected major taxa, nematode community structure and diversity indices in the integrated sediment column among treatments at the end of the experiment

\begin{tabular}{lllll}
\hline & \multicolumn{2}{l}{ Treatment } \\
\cline { 2 - 5 } & df & MS & Pseudo- $F$ & $P$ \\
\hline Total meiofauna & 3 & 1.36 & 3.23 & $\mathrm{~ns}$ \\
Turbellaria & 3 & 23.2 & 2.81 & $\mathrm{~ns}$ \\
Harpacticoida & 3 & 52 & 2.12 & $\mathrm{~ns}$ \\
Juvenile bivalves & 3 & 4690 & 12.3 & 0.0029 \\
Rotatoria & 3 & 9001 & 2.99 & 0.044 \\
Nematoda & 3 & 47,705 & 1.63 & $\mathrm{~ns}$ \\
Untransformed & 3 & 819 & 1.46 & $\mathrm{~ns}$ \\
Square-root transformed & 3 & 588 & 1.78 & 0.0305 \\
Fourth-root transformed & 3 & 480 & 2.14 & 0.013 \\
ES(30) & 3 & 1.68 & 0.98 & $\mathrm{~ns}$ \\
$H^{\prime}$ & 3 & 7.29 & 0.74 & $\mathrm{~ns}$ \\
$J^{\prime}$ & 3 & 7.17 & 0.92 & $\mathrm{~ns}$ \\
$d$ & 3 & 4.39 & 0.22 & $\mathrm{~ns}$ \\
\hline
\end{tabular}

$n s$ Not significant

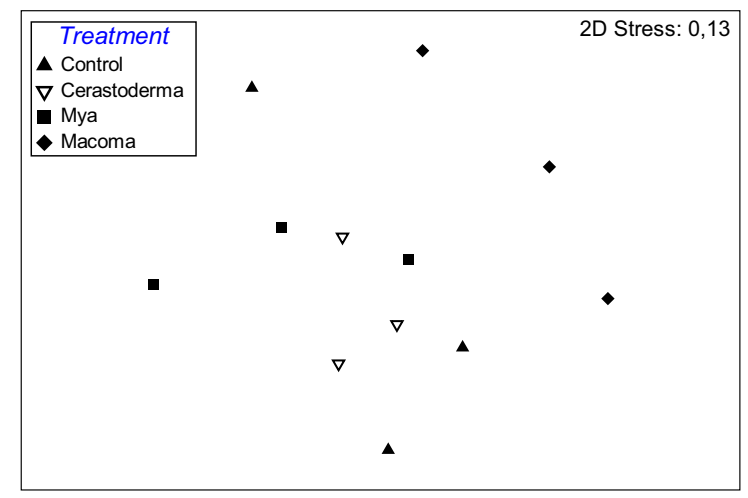

Fig. 4 Non-metric multidimensional scaling (MDS) ordinations of treatment similarity based on standardized square-root transformed nematode abundance data in the integrated sediment column at the end of the experiment

meiobenthos and nematodes, and influenced the composition of meiobenthic and nematode community at the sediment surface.

\section{Methods}

The effect of sediment sieving, homogenization and stabilization prior to the addition of macrofauna on meiobenthic community in this experiment is discussed in detail by Urban-Malinga et al. (2014). It was concluded that a vertical meiofauna distribution was re-established during the stabilization period, thus achieving a new equilibrium prior to the addition of macrofauna. Nematode densities recorded in the microcosms at the end of the experiment were not significantly different from those recorded in the field on the day of sediment sampling, suggesting no mortality of nematodes under the experimental conditions. Nematode community structure and composition in the treatments were also similar to the those recorded in the natural environment except in the Macoma treatment in which they were significantly different from the field community. With the exception of Viscosia viscosa (Bastian, 1865) de Man, 1890 and Eleutherolaimus spp. which were in low abundance at the study site ( 8 and 1.7 ind. $10 \mathrm{~cm}^{-2}$, respectively) and did not survive under experimental conditions, all other species recorded at the study site were also found in the microcosms. These observations suggest that our experimental procedure had little effect on nematode community composition, and therefore, recorded differences can be attributed to the presence of the three bivalve species.

\section{Effect on meiobenthos and nematodes}

The addition of the three bivalve species to the experimental microcosms had no significant effect on total meiofaunal or nematode density. There were, however, significantly reduced numbers of two major taxa, juvenile bivalves and rotifers, in the Macoma treatment compared to treatments with other bivalves. Only two specimens of juvenile bivalves were recorded in microcosms with Macoma (vs. 50-106 ind. $10 \mathrm{~cm}^{-2}$ in microcosms inhabited by other bivalves and $14-32$ ind. $10 \mathrm{~cm}^{-2}$ in defaunated sediment), whilst the numbers of rotifers were similar to those recorded in defaunated sediment (on average 6 and 3 ind. $10 \mathrm{~cm}^{-2}$, respectively vs. $70-117$ ind. $10 \mathrm{~cm}^{-2}$ in microcosms with other bivalves). Juvenile bivalve numbers were probably elevated in Cerastoderma and Mya microcosms owing to the presence of biofilms: faeces and pseudofaeces deposited at the sediment surface by these two bivalves presumably promoted the microbial community which in turn supported the microbial-feeding rotifers. In contrast, the mechanical disturbance of the sediment surface by 


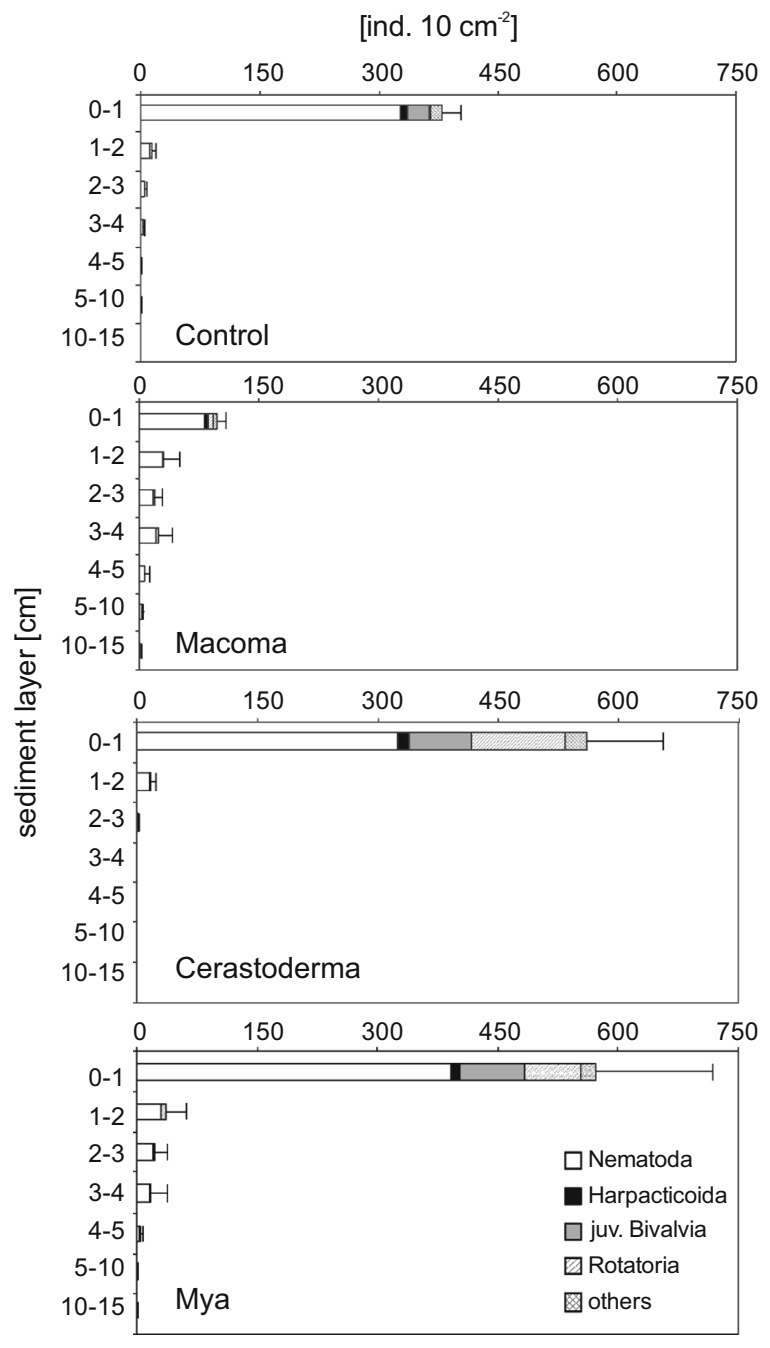

Fig. 5 Vertical distribution of meiofauna and major meiofaunal taxa (mean $\pm \mathrm{SE}$ ) in each treatment at the end of the experiment

Macoma activity and surface deposit-feeding, and its release of faeces to the subsurface sediment, were probably responsible for reduced numbers of these taxa in the Macoma treatment.

The observed reduction, although not significant, of the numbers of all other meiobenthic taxa in all Macoma microcosms compared to other treatments must be also noted. Interestingly, this decrease is similar for all the dominant major taxa (i.e. an average drop of $54-66 \%$ for Nematoda, $47-72 \%$ for Turbellaria and 47-68\% for Harpacticoida compared to other treatments). This may indicate meiofaunal mortality either due to competition for food with Macoma or physical disturbance by Macoma feeding activity and

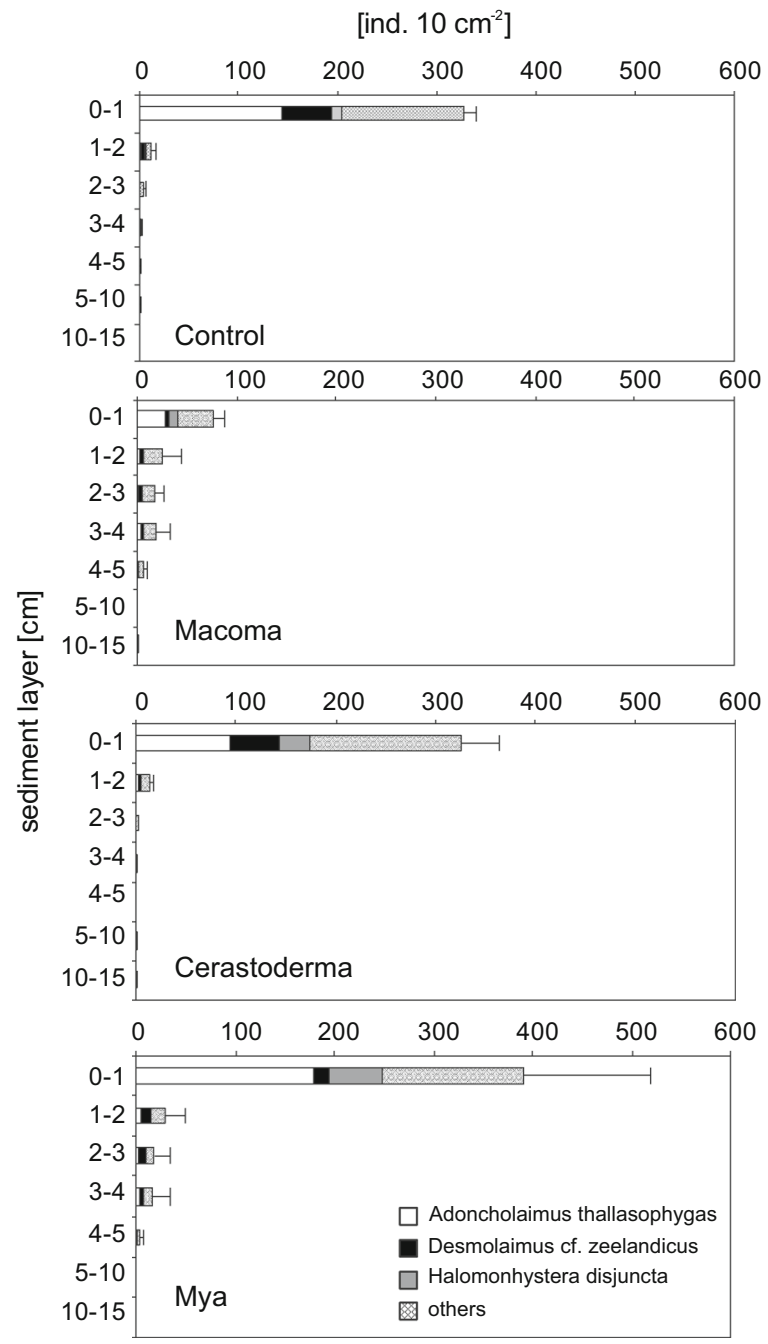

Fig. 6 Vertical distribution of nematodes (mean \pm SE) and numerical abundance of the dominant nematode species in each treatment at the end of the experiment

general movement. Reduced meiofaunal numbers in response to the activity of $M$. balthica were reported by Olafsson et al. (1993, 2005), whilst Reise (1981, 1983) observed stimulation of turbellarians in the presence of Macoma and attributed this to organic enrichment of the subsurface sediment $(2-4 \mathrm{~cm})$ where the Macoma exhalant siphon probably terminated. In our experiment, organic carbon contents were non-significantly enhanced in the subsurface sediment in Macoma treatment. They were also higher in the upper $4 \mathrm{~cm}$ in the $M y a$ treatment than in the defaunated sediment and other bivalve treatments. Hansen et al. (1996) suggested that the large "burrow" 
openings of $M$. arenaria might trap labile organic matter when the siphons close or retract, whilst repeated extensions and withdrawals of the long siphons may cause transport of the overlying water with associated organic suspension, faeces and pseudofaeces into the burrow, leading to enrichment of the surrounding sediment. All changes in vertical sediment characteristics observed in our experiment were, however, not significant, suggesting too short incubation time and/or too small number of replicates used to study changes in the sediment parameters (e.g. pore water samples were pooled together to obtain sufficient amount of pore water for analysis). Due to the same reasons, the overall effects of bivalves on meiobenthic and nematode communities, especially integrated over the sediment layers, were weak. It must be highlighted, however, that both time period and replicates number were sufficient to observe significant changes in the vertical profiles of nematode occurrence, especially in the top sediment layer. Nematode occurrence in Cerastoderma microcosms was largely limited to the sediment surface whilst in the Macoma and Mya treatments nematodes penetrated deeper sediment layers. The lack of response of meiobenthos to the presence of Cerastoderma was also reported in earlier studies (Reise, 1983; Kennedy, 1993) and can be related to the near-surface activity of this bivalve, having limited effect on subsurface sediment characteristics. Van Colen et al. (2012) observed a substantial effect of Cerastoderma on benthic processes, but these authors studied muddy sediments (vs. medium sand in our study) and larger North Sea specimens which potentially have a stronger effect on sediment characteristics.

In Mya microcosms, the majority of nematodes were also concentrated in the top sediment layer but, on average, $13 \%$ of the community penetrated to deeper sediment layers. A similar habitat extension was observed in Macoma microcosms, where nematodes were recorded to a depth of 10-15 cm and only $54 \%$ of the total meiofaunal abundance was limited to the top sediment layer. Similarly, Reise $(1981,1983)$ observed penetration of turbellarians to deeper layers of sandy sediments in the presence of Macoma. By contrast, in muddy sediment Olafsson et al. (1993) found no effect of Macoma on meiofauna distribution, but in such habitats, the typically severe chemical gradients are likely to be more important than bivalve activity in structuring interstitial communities.
We hypothesize that in our experiment, Macoma and Mya have also created favourable conditions for non-selective (A. elongatus, D. cf. zeelandicus) and surface deposit-feeding [Paracanthonchus spp., Paracyatholaimus proximus (Bütschli, 1874) Micoletzky, 1924)] nematodes, which penetrated deeper sediment layers in these microcosms compared to the defaunated sediment and the Cerastoderma treatment (data not shown).

Differences in the vertical distribution of nematode abundance and nematode species in the Macoma microcosms did not result, however, in significant changes in the vertical structure of the community. Results of pairwise tests showed that abundance changes in the top sediment layer $(0-1 \mathrm{~cm})$ were in fact responsible for differences in meiofaunal and nematode assemblages between treatments. The reduced numerical abundance of $A$. thalassophygas and $D$. cf. zeelandicus observed in the top sediment layer in Macoma microcosms, compared to all other treatments (including the field community), may be partly due to competition for food between these dominant nematodes and the bivalve and/or due to changes in food availability in response to bivalve mechanical disturbance (Braeckman et al., 2011a; Van Colen et al., 2012). Also, the abundance of the bacterial feeder, $H$. disjuncta, was significantly reduced in the presence of Macoma in comparison to other treatments probably due to sediment surface disturbance and the absence of a biofilm. These observed differences suggest that the release of pseudofaeces and faeces to the sediment surface by Cerastoderma and Mya and the associated creation of biofilms that facilitate the development of the microbial community may be a significant factor influencing the structure of the meiobenthic community, both at the meiobenthic higher taxa (juvenile bivalves and rotifers) and nematode species levels.

The densities of Macoma used in our experiment were higher than average natural densities of this bivalve, but the biomass corresponded to average macrobenthic biomass in the field. The fact that the effect of Macoma on the occurrence of rotifers, bivalve juveniles, and on nematodes (specifically the reduced abundance of $A$. thalassophygas, D. cf. zeelandicus and $H$. disjuncta) observed here is similar to that observed when another active surface deposit feeder, the polychaete Hediste diversicolor (O. F. Müller, 1776), is studied under the same experimental conditions (Urban-Malinga et al., 
2014) must be highlighted. This observation confirms the prominent role of macrobenthic functional traits in structuring meiobenthic communities. Since the bivalves described here co-occur in the natural environment, it would be interesting to investigate their interactions. There was no indication of any effects between sessile $M$. arenaria and C. glaucum under experimental condition (Urban-Malinga et al., 2014) but M. balthica living actively closer to the sediment surface than $M$. arenaria and feeding at the sediment surface is likely to interact with surface-dwelling C. glaucum.

Acknowledgments This study was financially supported by the Polish Ministry of Science and Higher Education (Grant Number N N304 072334). The staff of the Gdynia Aquarium are gratefully acknowledged for all their help and technical advice. The authors also wish to express their deepest thanks to Aleksander Drgas for help with sampling; Hanna Wróblewska, Sławka Gromisz, Katarzyna Horbowa, Maria Szymelfenig and Krzysztof Pawlikowski for their help with field and laboratory work. Dorota Burska is acknowledged for $\mathrm{CHN}$ and pore water nutrient content analyses. The authors also acknowledge MarBEF Funding which facilitated the collaboration between BUM and NB. We wish to thank two anonymous reviewers for their suggestions and constructive comments that considerably helped improve the quality of this manuscript.

\section{Compliance with ethical standards}

Conflict of interest We declare that no conflict of interests exists.

Open Access This article is distributed under the terms of the Creative Commons Attribution 4.0 International License (http:// creativecommons.org/licenses/by/4.0/), which permits unrestricted use, distribution, and reproduction in any medium, provided you give appropriate credit to the original author(s) and the source, provide a link to the Creative Commons license, and indicate if changes were made.

\section{References}

Anderson, M. J., R. N. Gorley \& K. L. Clarke, 2008. PERMANOVA+ for PRIMER: Guide to Software and Statistical Methods. PRIMER-E, Plymouth.

Austen, M. C., S. Widdicombe \& N. Villano-Pitacco, 1998. Effects of biological disturbance on diversity and structure of meiobenthic nematode communities. Marine Ecology Progress Series 174: 233-246.

Braeckman, U., C. Van Colen, K. Soetaert, M. Vincx \& J. Vanaverbeke, 2011a. Contrasting macrobenthic activities differentially affect nematode density and diversity in a shallow subtidal marine sediment. Marine Ecology Progress Series 422: 179-191.

Braeckman, U., P. Provoost, T. Moens, K. Soetaert, J. J. Middelburg, M. Vincx \& J. Vanaverbeke, 2011b. Biological vs. physical mixing effects on benthic food web dynamics. PLoS One 6(3): e18078.

Dame, R. F., 1993. Bivalve Filter Feeders in Estuarine and Coastal Ecosystem Processes. Springer, Berlin.

Dame, R. F., 1996. Ecology of Marine Bivalves: An Ecosystem Approach. Marine Science Series. CRC Press, Boca Raton.

Gili, J. M. \& R. Coma, 1998. Benthic suspension feeders: their paramount role in littoral marine food webs. Trends in Ecology and Evolution 13: 316-321.

Grasshoff, K., M. Erhardt \& K. Kremling, 1983. Methods of Sea Water Analysis. Verlag Chemie, Weinheim.

Gutierrez, J. L., C. G. Jones, D. L. Strayer \& O. O. Iribarne, 2003. Mollusks as ecosystem engineers: the role of shell production in aquatic habitats. Oikos 101: 79-90.

Hansen, K., G. M. King \& E. Kristensen, 1996. Impact of the softshell clam Mya arenaria on sulfate reduction in an intertidal sediment. Aquatic Microbial Ecology 10: 181-194.

Jones, C. G., J. H. Lawton \& M. Shachak, 1994. Organisms as ecosystem engineers. Oikos 69: 373-386.

Kautsky, N. \& S. Evans, 1987. Role of biodeposition by Mytilus edulis in the circulation of matter and nutrients in the Baltic coastal ecosystem. Marine Ecology Progress Series 33: 201-212.

Kennedy, A. D., 1993. Minimal predation upon meiofauna by endobenthic macrofauna in the Exe Estuary, south west England. Marine Biology 117: 311-319.

Levinton, J. S., 1995. Bioturbators as ecosystem engineers: control of the sediment fabric, inter-individual interactions, and material fluxes. In Jones, C. G. \& J. H. Lawton (eds), Linking Species and Ecosystems. Chapman and Hall, New York.

Ólafsson, E. B., 1986. Density dependence in suspensionfeeding and deposit-feeding populations of the bivalve Macoma balthica: a field experiment. Journal of Animal Ecology 55: 517-526.

Olafsson, E., 2003. Do macrofauna structure meiofauna assemblages in marine soft-bottoms? A review of experimental studies. Vie Milieu 53: 249-265.

Olafsson, E. \& R. Elmgren, 1991. Effects of biological disturbance by benthic amphipods Monoporeia affinis on meiobenthic community structure: a laboratory approach. Marine Ecology Progress Series 74: 99-107.

Olafsson, E., R. Elmgren \& O. Papakosta, 1993. Effects of the deposit-feeding benthic bivalve Macoma balthica on meiobenthos. Oecologia 93: 457-462.

Ólafsson, E. B., J. Ullberg \& N. L. Arrovo, 2005. The clam Macoma balthica prevents in situ growth of microalgal mats: implications for meiofaunal assemblages. Marine Ecology Progress Series 298: 179-188.

Piesik, Z., K. Obolewski \& A. Strzelczak, 2009. Distribution of common bivalves in the Polish coastal zone of the Baltic Sea. Journal of Ecology and Protection of the Coastline, Baltic Coastal Zone 13: 33-47.

Platt, H. M. \& R. M. Warwick, 1983. Freeliving marine nematodes. Part I. British Enoplids. In Kermack, D. M. \& R. S. K. Barnes (eds), Synopses of the British Fauna (New Series) No. 28. Cambridge University Press, Cambridge.

Platt, H. M. \& R. M. Warwick, 1988. Freeliving marine nematodes. Part II. British Chromadorids. In Kermack, D. M. \& R. S. K. Barnes (eds), Synopses of the British Fauna (New Series), No. 38. E.J. Brill/Dr. W. Backhuys, Leiden. 
Reise, K., 1981. High abundance of small zoobenthos around biogenic structures in tidal sediments of the Wadden Sea. Helgolander Meeresuntersuchungen 34: 413-425.

Reise, K., 1983. Biotic enrichment of intertidal sediments by experimental aggregates of the deposit-feeding bivalve Macoma balthica. Marine Ecology Progress Series 12: 229-236.

Steyaert, M., T. Deprez, M. Raes, T. Bezerra, I. Demesel, S. Derycke, G. Desmet, G. Fonseca, M. de Assuncăo Franco, T. Gheskiere, E. Hoste, J. Ingels, T. Moens, J. Vanaverbeke, S. Van Gaever, S. Vanhove, A. Vanreusel, D. Verschelde \& M. Vincx, 2005. Electronic Key to the freeliving marine Nematodes [available on internet at http:// nemys.ugent.be/].

Urban-Malinga, B., A. Drgas, S. Gromisz \& N. Barnes, 2014. Species-specific effect of macrobenthic assemblages on meiobenthos and nematodes from shallow sandy habitat. Marine Biology 161: 195-212.

Van Colen, C., F. Rossi, F. Montserrat, M. G. I. Andersson, B. Gribsholt, et al., 2012. Organism-sediment interactions govern post-hypoxia recovery of ecosystem functioning. PLoS One 7(11): e49795.
Warwick, R. M., A. J. McEvoy \& S. F. Thrush, 1997. The influence of Atrina zelandica Gray on meiobenthic nematode diversity and community structure. Journal of Experimental Marine Biology and Ecology 214: 231-247.

Warwick, R. M., H. M. Platt \& P. J. Somerfield, 1998. Freeliving marine nematodes. Part III. Monhysterids. In Barnes, R. S. K. \& J. H. Crothers (eds), Synopses of the British Fauna (New Series) No. 53. Field Studies Council, Shrewsbury.

Warzocha, J., 1994. Spatial distribution of macrofauna in the southern Baltic in 1983. Bulletin of Sea Fisheries Institute, Gdynia 1(131): 47-59.

Warzocha, J., 1995. Classification and structure of macrofaunal communities in the southern Baltic. Archive of Fishery and Marine Research 42: 225-237.

Wieser, W., 1953. Beziehungen zwischen Mundhhlengstalt, Ernahrungsweise und Vorkommen bei Freilebenden marinen Nematoden. Arkiv fur Zoologie 2: 439-484. 